\title{
Stability of DC Voltage Droop Controllers in VSC HVDC Systems
}

Thams, Florian; Suul, Jon Are; D’Arco, Salvatore; Molinas, Marta; Fuchs, Friedrich Wilhelm

Published in:

Proceedings of 2015 IEEE Eindhoven PowerTech

Link to article, DOI:

10.1109/PTC.2015.7232614

Publication date:

2015

Document Version

Peer reviewed version

Link back to DTU Orbit

Citation (APA):

Thams, F., Suul, J. A., D’Arco, S., Molinas, M., \& Fuchs, F. W. (2015). Stability of DC Voltage Droop Controllers in VSC HVDC Systems. In Proceedings of 2015 IEEE Eindhoven PowerTech IEEE Press.

https://doi.org/10.1109/PTC.2015.7232614

\section{General rights}

Copyright and moral rights for the publications made accessible in the public portal are retained by the authors and/or other copyright owners and it is a condition of accessing publications that users recognise and abide by the legal requirements associated with these rights.

- Users may download and print one copy of any publication from the public portal for the purpose of private study or research.

- You may not further distribute the material or use it for any profit-making activity or commercial gain

- You may freely distribute the URL identifying the publication in the public portal 


\title{
Stability of DC Voltage Droop Controllers in VSC HVDC Systems
}

\author{
, ${ }^{* \dagger}$ Florian Thams, ${ }^{*}+$ J Jon Are Suul, ${ }^{\dagger}$ Salvatore D'Arco, ${ }^{*}$ Marta Molinas, ${ }^{\dagger}$ Friedrich Wilhelm Fuchs \\ *Department of Electric Power Engineering \\ Norwegian University of Science and Technology \\ 7491 Trondheim, Norway \\ florian.thams@gmx.de \\ ${ }^{\ddagger}$ SINTEF Energy Research \\ 7465 Trondheim, Norway \\ Jon.A.Suul@sintef.no \\ salvatore.darco@sintef.no \\ $\dagger$ Institute of Power Electronics \\ Christian-Albrechts-University of Kiel \\ 24118 Kiel, Germany \\ fwf@tf.uni-kiel.de \\ "Department of Engineering Cybernetics \\ Norwegian University of Science and Technology \\ 7491 Trondheim, Norway \\ marta.molinas@ntnu.no
}

\begin{abstract}
Future multi-terminal HVDC systems are expected to utilize de voltage droop controllers and several control implementations have been proposed in literature. This paper first classifies possible de droop implementations in a simple framework. Then, the small-signal stability of a VSC-based converter station is analyzed for all the identified droop control schemes. The stability range for the system is determined as a function of the droop gain and is used to compare the flexibility and robustness of the implementations. The comparisons reveal that the droop implementations based on the ac current and dc voltage achieve a wider stability region than the other schemes and a limited sensitivity to the droop gain.
\end{abstract}

Index Terms-DC voltage droop control, power transfer capability, stability, VSC HVDC systems

\section{INTRODUCTION}

Offshore wind farms are acknowledged to play a critical role to accomplish the European Union energy policy targets [1]. The present trend in the development of offshore wind farms is towards larger installed power and longer distances from shore. In these conditions HVDC technologies become the preferred technical solution for the power export to shore [2]. In the North Sea, the HVDC links planned for wind farm integration and the HVDC interconnectors for transnational power transmission are expected to be merged into a multiterminal HVDC (MT-HVDC) grid [3]-[6]. A crucial aspect for the operation of such a large MT-HVDC is the operational reliability since any malfunction could have a significant economic impact. In this perspective, it should be avoided that the regulation of the dc voltage and the intertwined regulation of the power flow between the terminals should rely on an approach where one single unit is assigned a dominant role. Instead, a distributed control architecture where multiple units are actively participating in the control of the grid based on local measurements is preferable. Indeed, a decentralized architecture is inherently more robust against outages and more effective in case of power fluctuations that exceed the available control range of a single terminal [7]. Several alternative strategies for distributed dc voltage control have been proposed in the technical literature. A common element in most of these control strategies is the presence of a dc voltage droop mechanism [8]-[11]. Despite that the general operating principle of dc droop is identical for the different implementation schemes, the use of different control objectives and different feed-back signals can have significant impact on the dynamic performances and the stability properties. However, these dc droop implementations are usually analyzed separately or by comparing only a few selected cases. For systematically addressing the analysis and comparison of different control schemes, this paper proposes a classification framework for the dc voltage droop implementations in MT-HVDC systems. Moreover, a comprehensive analysis based on small-signal models of the various droop categories is provided to assess the impact of the implementation scheme on the system eigenvalues and on stability. The results from this analysis indicate that a droop controller combining the ac current and the dc voltage offers the widest stability range and the highest robustness against controller tuning.

\section{ClasSIFICATION OF DC VOLTAGE DROOP CONTROLLERS FOR MT-HVDC}

In general, a droop control scheme introduces a linear relationship between two electrical variables in the form:

$$
y=y^{*}+k_{\text {droop }}\left(x-x^{*}\right)
$$

where $k_{\text {droop }}$ is referred as droop gain, $x^{*}$ and $y^{*}$ are the set points and $x, y$ are the measured variables respectively. In the specific case of dc voltage droop control for MT-HVDC, the dc voltage is used in each implementation as $y$ variable of this equation, so that $k_{\text {droop }}$ defines the deviation of $v_{d c}$ for a variation the other electric variable. For the other variable more options are possible. A common classification in 
TABLE 1 EXPRESSIONS FOR THE DIFFERENT DROOP IMPLEMENTATIONS AND REFERENCE TO CORRESPONDING LITERATURE

\begin{tabular}{|c|c|c|c|}
\hline \multicolumn{2}{|c|}{ Current based implementations } & \multicolumn{2}{|c|}{ Power based implementations } \\
\hline$i_{d c}$ & $i_{d, a c}$ & $p_{d c}$ & $p_{a c}$ \\
\hline Case 1, ref. Fig. 3a) & Case 2, ref. Fig. 3b) & Case 5, ref. Fig. 3e) & Case 6, ref. Fig. 3f) \\
\hline$i_{d c}=i_{d c}^{*}+\frac{1}{k_{d r o o p}}\left(v_{d c}-v_{d c}^{*}\right)$ & $i_{d, a c}=i_{d, a c}^{*}+\frac{1}{k_{\text {droop }}}\left(v_{d c}-v_{d c}^{*}\right)$ & $p_{d c}=p_{d c}^{*}+\frac{1}{k_{d r o o p}}\left(v_{d c}-v_{d c}^{*}\right)$ & $p_{a c}=p_{a c}^{*}+\frac{1}{k_{\text {droop }}}\left(v_{d c}-v_{d c}^{*}\right)$ \\
\hline $\begin{array}{c}\text { Found in [12], [13], [14], [15], [16], } \\
\text { [17], [18], [19] and [20]. } \\
\text { Does not include a PI controller. }\end{array}$ & $\begin{array}{l}\text { Found in [21]. } \\
\text { Does not include a PI } \\
\text { controller. }\end{array}$ & $\begin{array}{l}\text { Found in [11], [26], [27] and } \\
\text { [28], mainly focusing on power } \\
\text { sharing and not on stability } \\
\text { investigations. }\end{array}$ & Found in [27]. \\
\hline Case 3, ref. Fig. 3c) & Case 4, ref. Fig. 3d) & Case 7, ref. Fig. 3g) & Case 8, ref. Fig. 3h) \\
\hline$v_{d c}=v_{d c}^{*}+k_{d r o o p}\left(i_{d c}-i_{d c}^{*}\right)$ & $v_{d c}=v_{d c}^{*}+k_{d r o o p}\left(i_{d, a c}-i_{d, a c}^{*}\right)$ & $v_{d c}=v_{d c}^{*}+k_{d r o o p}\left(p_{d c}-p_{d c}^{*}\right)$ & $v_{d c}=v_{d c}^{*}+k_{d r o o p}\left(p_{a c}-p_{d, a c}^{*}\right)$ \\
\hline $\begin{array}{c}\text { Presented in [10], [22], [23], [24] and } \\
{[25] .} \\
\text { Includes a PI controller. }\end{array}$ & $\begin{array}{l}\text { Not present in literature. } \\
\text { Includes a PI controller. }\end{array}$ & Found in [29] and [30]. & $\begin{array}{c}\text { Used in [30] for a rectifier } \\
\text { scenario. }\end{array}$ \\
\hline
\end{tabular}

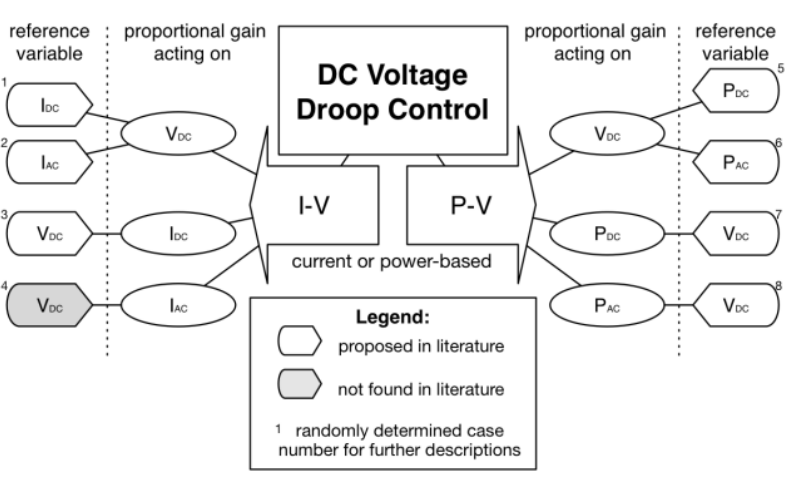

Fig. 1. Overview and classification of de voltage droop controllers

literature is based on droop schemes utilizing active power or current as additional variable [8]. However, both active power and current can be referred to the ac side or to the $\mathrm{dc}$ side. A critical aspect for the droop implementation is the decision on which electrical variable the droop gain acts and correspondingly which electrical variable is controlled by a subsequent PI-controller. As a summary, four options are considered in this paper for the additional variable, namely: the power on the dc side $p_{d c}$, the active power on the ac side $p_{a c}$, the current on the dc side $i_{d c}$, and the active, direct axis, component of the current on the ac side $i_{d}$. Depending on the choice on which electric variable the droop gain is acting this results in eight possible combinations and related droop schemes implementations.

An overview of these droop implementations is shown in Fig. 1 and in Table 1. The table reports also literature references for each scheme except for the implementation referred as case 4 that has not been explicitly presented before. Control schematics for the 8 cases from Fig. 1 are shown in Fig. 2. It should be noted that the schemes referred as case 1 and 2 directly output a direct axis current reference and do not need an additional PI as the other schemes. This leads to a lower model complexity and to a dynamic behavior mainly determined by the current controller.

\section{Stability ANalysis of DC Voltage Droop CONTROLLERS FOR MT-HVDC}

The implementations options presented in Table 1 and Fig. 2 all have a similar principle of operation and their
TABLE 2: VALUES OF THE CONTROLLER GAINS

\begin{tabular}{|l|l|l|l|l|}
\hline Case & $k_{p c d}$ (p.u.) & $k_{i c d}$ (p.u.) & $k_{p c q}$ (p.u.) & $k_{i c q}$ (p.u.) \\
\hline Case 1 & - & - & 0.01 & 898 \\
\hline Case 2 & - & - & 0.01 & 898 \\
\hline Case 3 & 4 & 10638 & 0.01 & 898 \\
\hline Case 4 & 1.0885 & 6678 & 0.01 & 898 \\
\hline Case 5 & 0.575 & 3130 & 0.01 & 898 \\
\hline Case 6 & 0.2 & 2699 & 0.01 & 898 \\
\hline Case 7 & 2.6 & 15569 & 0.01 & 898 \\
\hline Case 8 & 1.2 & 12972 & 0.01 & 898 \\
\hline
\end{tabular}

steady state performances can be also almost equivalent at the condition that the droop gain is properly scaled. However, the dynamic performances and the stability range can be expected to present much wider variations. In order to assess the comparative performances of the 8 options presented, a common reference test configuration including a HVDC terminal with de voltage droop has been analyzed. A small signal linearized model has been derived for the reference system together with its equivalent state space representation.

\section{A. Reference Test Case}

A configuration consisting of a single VSC HVDC converter terminal connected to an ac and a dc grid equivalent is assumed as a test case, as represented in Fig. 3. The converter terminal model is based on the VSC representation described in [31] and its control scheme is shown in Fig. 4. The converter is assumed to be synchronized to the ac grid through a Phase Locked Loop (PLL) and operated with conventional inner-loop PI current controllers in the Synchronous Reference Frame (SRF). The PI controller of the current controller is tuned by using the modulus optimum criterion [32]. The model also includes active damping to suppress LC oscillations. A constant reactive power controller generates the reference value $i_{q}^{*}$. The droop controllers are implemented as outer controller for the direct axis component of the current. The numerical values for the gains of the droop controller, given in Table 2, have been selected to ensure comparable performances. In particular, if a PI controller is present, its tuning has been set to achieve a $5 \%$ overshoot in the active power for a $5 \%$ step in the dc voltage reference. A linearized small-signal model of the system configuration in per unit (p.u.) is developed for 


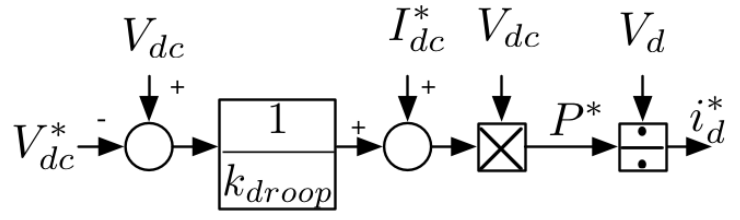

a) Case 1: V-I $\mathrm{I}_{\mathrm{dc}}$ Droop without PI controller

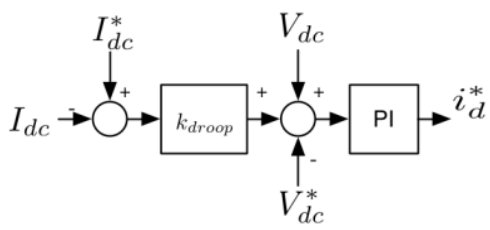

c) Case 3: $I_{d c}-V$ Droop with PI controller

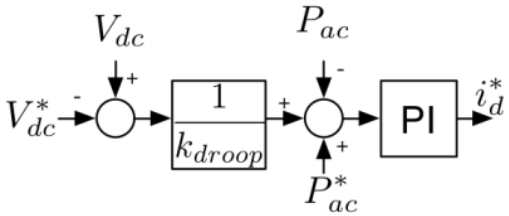

f) Case 6: V-P $\mathrm{ac}_{\mathrm{ac}}$ Droop

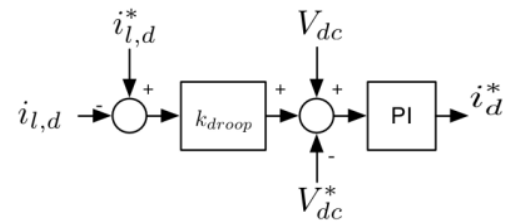

d) Case 4: $I_{a c}-V$ Droop with PI controller

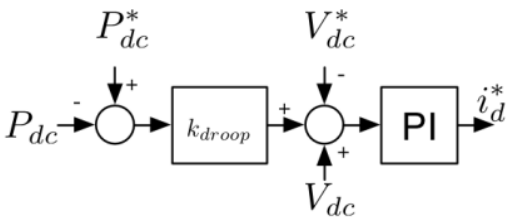

g) Case 7: $P_{d c}-V$ Droop

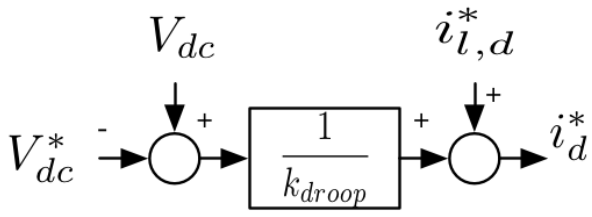

b) Case 2: V-I $\mathrm{I}_{\mathrm{ac}}$ Droop without PI controller

Fig. 2. Block diagrams of implementations for the different droop implementations

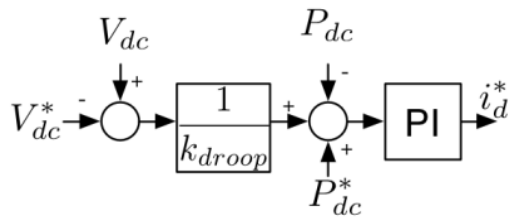

e) Case 5: V-P $\mathrm{P}_{\mathrm{dc}}$ Droop

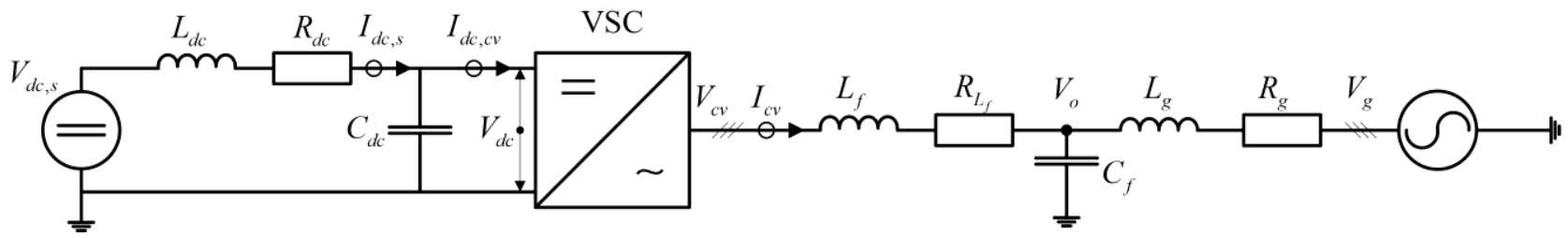

Fig. 3. Overview of electrical system for a HVDC converter terminal

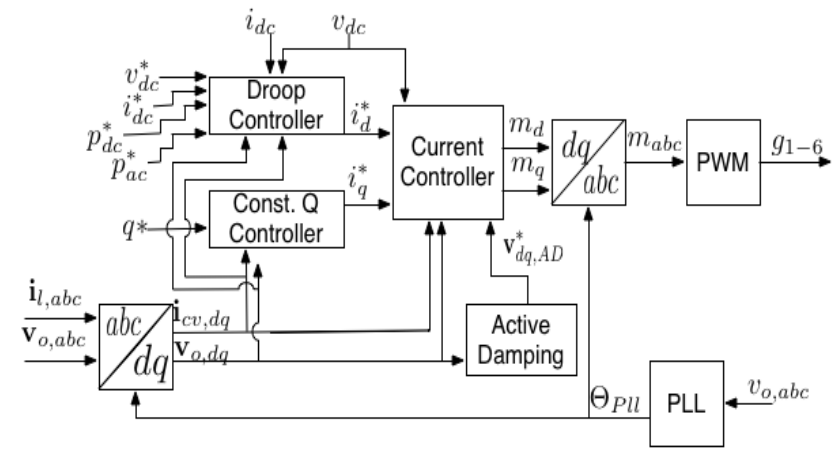

Fig. 4. Overview of control system

each case from Fig. 2. The base values and the parameter values are given in the Appendix.

\section{B. Comparison of Damping Ratios}

As a first step, the eigenvalues of the small-signal models developed for each of the 8 cases from Fig. 2 are compared under normal operating conditions. For the steady state evaluation, the value of current-based droop gain $k_{\text {droop }, I}=0.2$ is selected. In order to ensure a fair comparison, the powerbased droop variable $k_{\text {droop, } P}=0.1934$ is calculated [5].

The average damping ratio of a set of relevant eigenvalues where the location is different between the cases is compared as a first measure of dynamic properties. This measure indicates which of the implementations present a comparable well damped dynamic behavior and which are

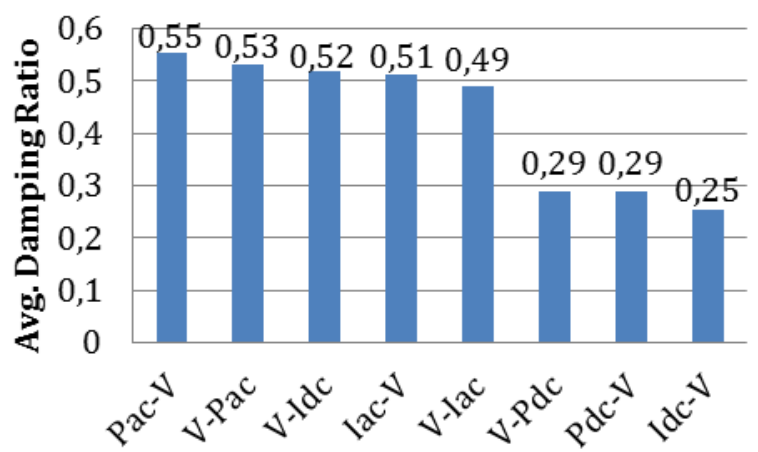

Fig. 5: Average damping ratio of relevant eigenvalues

prone to poorly damped oscillations associated with one or more modes.

The results, shown in Fig. 5, reveal remarkable differences between the cases. Indeed, the droop implementations combining a variable from the ac side $\left(p_{a c}\right.$ and $i_{d}$ ) with the dc voltage $v_{d c}$ offer a relatively higher average damping ratio. For example, the combination of $v_{d c}$ and $p_{a c}$ presents a superior behavior compared to the case where $p_{d c}$ is used (45-47\% higher average damping ratio).

By contrast, the differences between the implementations based on the same variables but with opposite roles (e.g. case 1 and 3) are comparatively much smaller with the only notable exception of the cases where $i_{d c}$ is used. Indeed, in the case 1, even if not directly included in the droop, the 


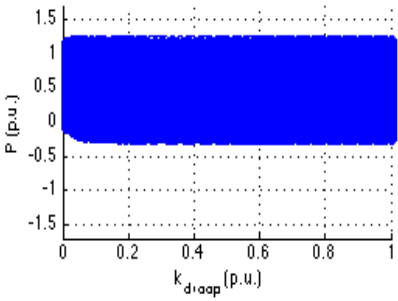

a) Stability range of Case 1

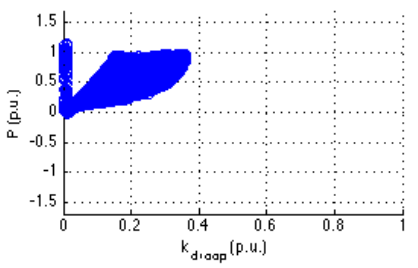

e) Stability range of Case 5

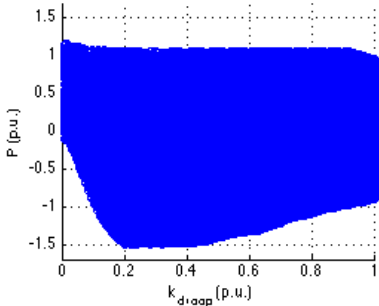

b) Stability range of case 2

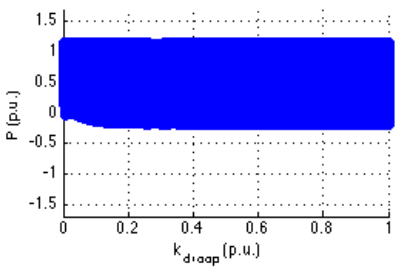

f) Stability range of Case 6

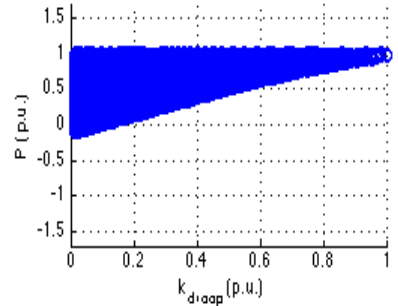

c) Stability range of Case 3

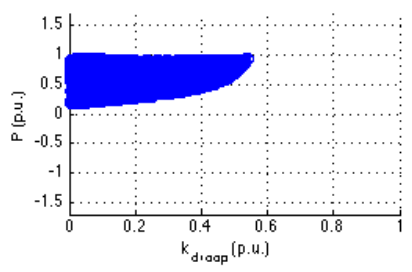

g) Stability range of Case 7

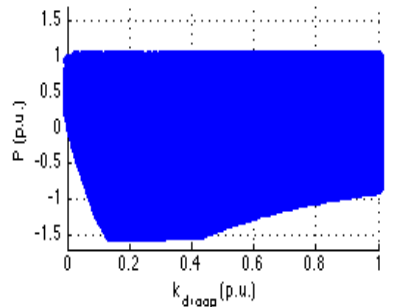

d) Stability range of Case 4

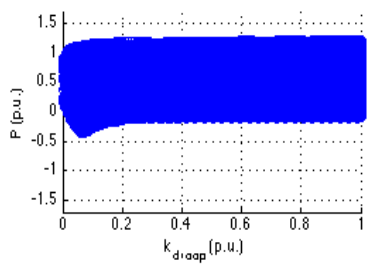

g) Stability range of Case 8

Fig. 6. Stability range of the different droop implementations as a function of droop gain

voltage at the ac-side LC filter is used to calculate the current reference value. In the case 3, the reference value for the current controller depends only on dc variables. Thus, a link between the ac- and dc-sides is established within the control system for the case 1 and not for the case 3 , which leads to a higher average damping ratio for case 1 .

\section{Comparison of Stability Ranges}

Previous studies have demonstrated that the value of the droop gain can strongly influence the system stability. Thus, in this section it is investigated how the stability range is influenced by the droop gain for a wide range of operating conditions. The stability region is defined as the set of stable operating conditions in terms of active power flow and droop gain values. The resulting stability regions, shown in Fig. 6, indicate significant differences between the implementations. As a further investigation, the critical eigenvalues at the stability limits are analyzed by a participation factor analysis and an eigenvalue parametric sensitivity analysis.

\section{1) Case 1: V-I $I_{d c}$ Droop without PI controller}

The stability range of case 1 indicates that an active power transfer up to almost rated power is possible in inverter operation but not in rectifier operation. The participation factor analysis of the critical eigenvalues for the inverter operation limit reveals a high participation of the states representing the $q$-component of the grid current $i_{g, q}^{*}$, the integrator state of the outer controller of the q-component $\chi_{q}$ and the $q$-component of the voltage at the LC-filter $v_{o, q}$. Parametric sensitivity analysis of the corresponding complex conjugate pair of critical eigenvalues is shown in Fig. 7 with the real part of the sensitivity plotted in blue and the imaginary part in red. The analysis reveals high sensitivity to circuit parameters $\left(r_{d c}, c_{f}\right.$ and $l_{g}$ as defined in Fig. 3) and that a reduction of $k_{p c q}$ would improve the limits. However, this is only possible to a limited extent due to the already low value. Moreover, a slight improvement can be achieved for a higher value of $k_{a d}$ indicating that the limit is caused by oscillations on the ac side.

The participation factor analysis of the conjugate complex pair of the critical eigenvalues of the rectifier limit reveals a

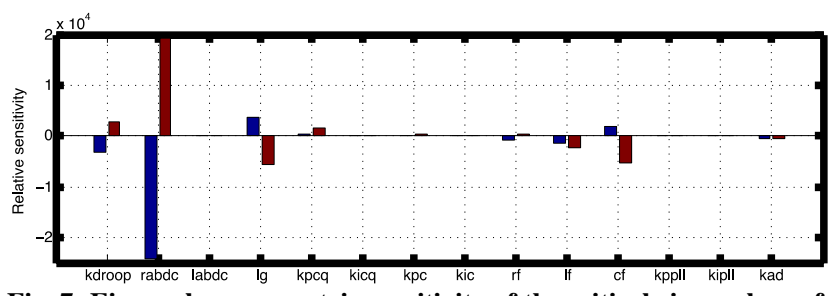

Fig. 7: Eigenvalue parametric sensitivity of the critical eigenvalues of the inverter limit

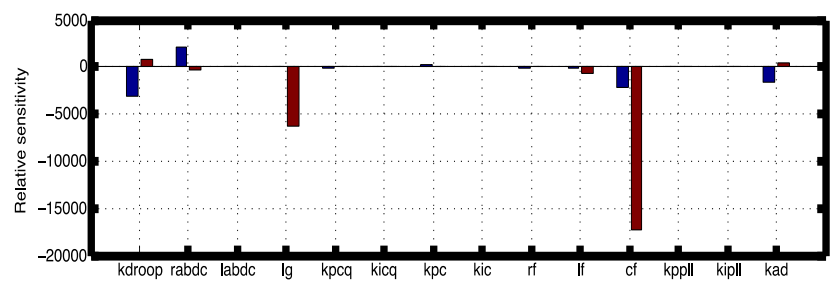

Fig. 8 : Eigenvalue parametric sensitivity of the critical eigenvalues of the rectifier operation limit

high participation of the states representing the d-component of the grid current $i_{g, d}$ and the d-component of the voltage at the LC-filter $v_{o, d}$. The eigenvalue parametric sensitivity analysis of the critical eigenvalue with positive imaginary part is shown in Fig. 8 indicating again high sensitivities to the electrical circuit parameters. Moreover, a possible improvement is shown for an increasing $k_{a d}$.

These results indicate that both inverter and rectifier operation limits cannot be easily improved by acting on the tuning of the current or outer controller. However, the stability range can be improved by the tuning of the active damping as shown in Fig. 9 a), indicating that the stability limits are associated with ac oscillations. It should also be noted that despite this implementation is frequently cited in literature, the active power transfer capability can be rather limited without dedicated efforts in tuning controller parameters.

\section{2) Case 2: V-I I Droop without PI controller}

The stability range for this implementation, shown in Fig. $6 \mathrm{~b}$ ), is relatively large compared to Case 1 . The rectifier 


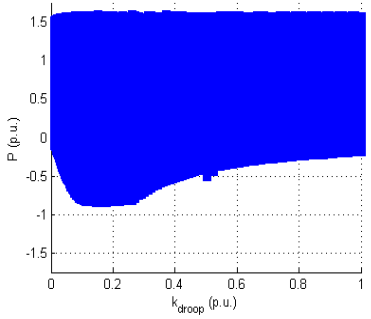

a) Stability range of Case 1 improved active damping

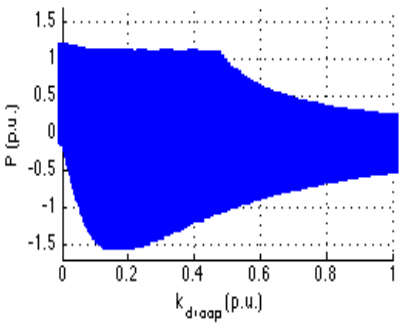

e) Stability range of Case 5 -reduced controller gains

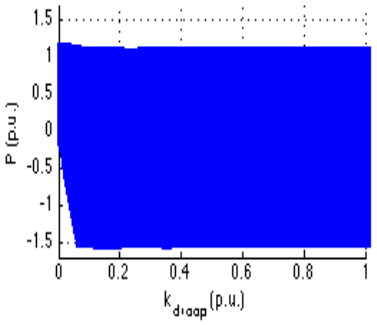

b) Stability range of Case 2 increased $\mathrm{v}_{\mathrm{dc}}^{*}=1.95$ p.u.

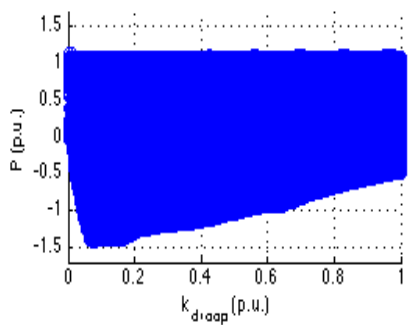

f) Stability range of Case 6 reduced controller gains

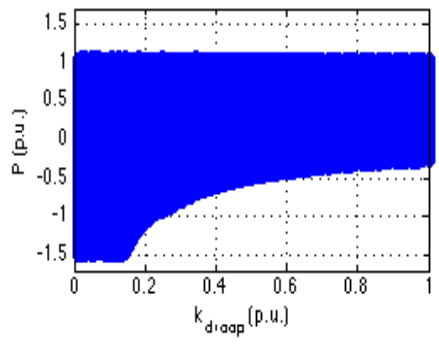

c) Stability range of Case 3-reduced controller gains

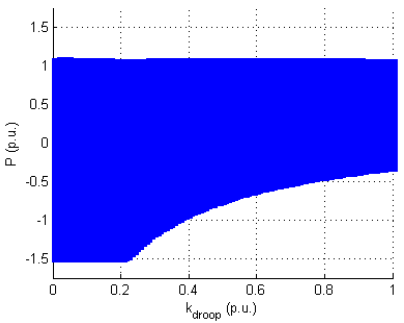

g) Stability range of Case 7 -reduced controller gains

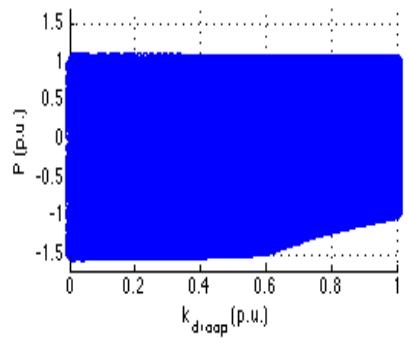

d) Stability range of Case 4 reduced controller gains

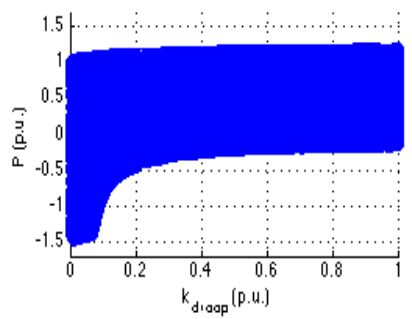

h) Stability range of Case 8 reduced controller gains

Fig. 9: Improved stability ranges of the different droop implementations as a function of the droop gain

power transfer limit for $k_{\text {droop }}>0.4$ is related to the selected dc voltage reference set point $v_{d c}^{*}$ and, thus, the operating point of the converter. Thus, it is worth to mention that the stability range can be improved by choosing a higher reference value for the dc voltage (e.g. an extreme value of $v^{*}{ }_{d c}=1.9$ is resulting in a very wide stability range as shown in Fig. 9 b)).

For lower values of $k_{d r o o p}$ the analysis of the critical eigenvalues shows a high participation of $v_{o, d}, i_{g, d}$ and $v_{d c}$. The eigenvalue parametric sensitivity analysis indicates a high sensitivity to electric parameters $\left(l_{g}, r_{d c}\right.$ and $\left.c_{f}\right)$. Thus, states and parameters from both ac and the dc sides play a significant role. It should also be noted that as for any of the implementation relying on the inverse of $k_{\text {droop }}$, a low value of the droop coefficient will lead to a very high gain in the system which can cause instability when $k_{\text {droop }}$ is approaching zero. The analysis of the inverter limit is similar to the analysis of case 1 and therefore not further discussed.

\section{3) Case 3: $I_{d c}-V$ Droop}

The results for case 3 indicate that only a stable inverter operation is possible at rated power and that the stability range is decreasing for increasing values of $k_{\text {droop }}$. The analysis of the inverter limit reveals similar results as in the case 1 . The participation factor analysis of the conjugate complex pair of critical eigenvalues of the rectifier limit shows a high participation of $v_{d c}, i_{d c}$, and $\chi_{d}$ while the sensitivity analysis reveals a very high sensitivity to $r_{d c}$. Further investigations indicates that by a reduction of $k_{i c d}$, the integral gain of the d-component outer controller, the stability range can be improved significantly ( $k_{i c d}$ reduced by factor 100 is shown in Fig. 9 c)). Thus, the bandwidth of the PI controller within the droop controller needs to be reduced to improve the active power transfer capability. Similarly as for Case 2, the stability range can also be extended by increasing the value of the dc voltage reference.

\section{4) Case 4: $I_{a c}-V$ Droop}

The stability range of case 4 is quite similar to case 2 . The analysis of the rectifier limit is similar to case 1 and is not further discussed. The analysis of critical eigenvalues of the inverter limit for very small values of $k_{\text {droop }}$ indicates a high participation of $v_{d c}$ and $\chi_{d}$, the integral state of the droop controller. A high sensitivity to not tunable parameter $\left(r_{d c}, l_{g}\right.$, $l_{f}$ ) can be observed. Similar to case 3 the stability range can be improved by a reduction of $k_{i c d}\left(k_{i c d}\right.$ reduced by factor 10 as shown in Fig. 9). The decreasing stability range for higher values of $k_{\text {droop }}$ is similar to case 2 and caused by the dc voltage reference set point.

\section{5) Case 5: V-P $P_{d c}$ Droop}

For case 5, a rather small stability range can be observed and almost without any stable rectifier operation. The analysis of the critical eigenvalues rectifier operation stability limit reveals a high participation of the states representing $v_{d c}$ and $\chi_{d}$, the integral state of the droop controller. The eigenvalue parametric sensitivity analysis indicates a high sensitivity to not tunable parameters. However, an improvement can be achieved by a reduction of the integral gain of the current controller (results with $k_{i c d}$ reduced by factor 100 is shown in Fig. 9 e)). Hence, a reduction of the PI controller bandwidth within the droop controller is necessary to achieve a sufficient stability range. The stability range can be further improved by a reduction of the active power reference value, $p^{*}$, and by increasing the dc voltage reference as discussed for the previous cases.

The inverter limit of the improved stability range in Fig. 9 e) differs from the other stability ranges. The analysis for low values of $k_{\text {droop }}$ indicates similar results as discussed in case 1 . However, the analysis for higher values shows a high participation of $v_{d c}$ and $i_{d c}$. The eigenvalue parametric sensitivity analysis of the critical eigenvalues reveals a high sensitivity to not tunable parameter of the dc side $\left(r_{d c}\right.$ and $\left.l_{d c}\right)$, which indicates that for an increasing value of the droop gain 
increasing dc oscillations are the reason for the decreasing stability range. These are caused by the instability effects of constant power loads in a simple LC circuit [33], and the simplified dc side equivalent used in this case is a worst case for such oscillations. Thus, a more accurate dc-side model or a dc-source with internal damping would attenuate this problem. It can also be shown that the stability range can be improved slightly for a reduction of the reference value of the active power $p$ and significantly for higher values of $r_{d c}$.

\section{6) Case 6: V-P $P_{a c}$ Droop}

The stability range of case 6 in the chosen configuration is similar to the one of case 1 . Almost no rectifier operation is possible whereas stable inverter operation is possible up to 1 p.u. The analysis of the inverter limit indicates the same results as for case 1; the limit is also caused by ac oscillations and can be improved by an optimized active damping tuning.

However, the analysis of the rectifier limit shows a high participation of the states $i_{g, d}$, the grid current, $v_{o, d}$, the voltage at the LC filter, and $\chi_{d}$, the integral state of the droop controller. The sensitivity analysis indicates a high sensitivity to not tunable parameter and possible improvements by tunable controller gains $\left(k_{p c d}, k_{p c}\right)$. These are conflicting with other eigenvalues or the critical eigenvalues of the upper limit. A significant improvement is possible by a reduction of the integral gain of the droop controller, $k_{i c d}$. The stability range for a reduction of $k_{i c d}$ by factor 10 is shown in Fig. $9 \mathrm{f}$ ). It is worth to mention that the stability range decreases again over a certain value of $k_{i c d}$ (the result is then similar to the one of case 5 with a decreasing inverter limit for increasing values of the droop gain). Hence, the stability range of this implementation depends also on the controller bandwidth. Similarly to case 5 , the stability range can also be slightly improved by reducing the active power reference or by increasing the dc voltage reference.

\section{7) Case 7: $P_{d c}-V$ Droop}

Similarly to Case 5 a rather small stability range with a decreasing inverter operation limit for increasing droop gain values and no stable rectifier operation can be observed. The analysis of the inverter limit indicates that as in the case 1 it is caused by ac oscillations. The analysis of critical eigenvalues of the rectifier operation limit reveals a high participation of the states representing the dc voltage and the integral state of the droop controller. The sensitivity analysis shows a high sensitivity to not tunable parameter and sensitivity to the proportional gain of the current controller in the opposite direction than in the upper limit. Similarly to previous cases, a reduction of $k_{i c d}$ leads to a significant improvement of the stability range $\left(k_{i c d}\right.$ reduced by factor 100 as shown in Fig. 9 g)). As in previous cases, improvements can be obtained by a reduced active power reference or by an increased dc voltage reference.

\section{8) Case 8: $P_{a c}-V$ Droop}

The stability range and the analysis of the limits are similar to case 6 . The upper limit is caused by ac oscillations while the lower limit by the controller bandwidth. Again, the stability range can also be improved by increasing the dc voltage reference.
As a summary, the stability range in most of the cases is dependent on the tuning of the controllers in the system, resulting in a wide stability range only if the controller bandwidth is maintained low. However, Case 2 and Case 4, which are both utilizing the dc voltage and the ac-side current present an inherently wide stability range.

\section{CONCLUSION}

This paper proposes a classification of implementations for the dc voltage droop control in a MT-HVDC systems. Furthermore, eight different droop implementations are identified and assessed in terms of their impact on the dynamic performances and stability range of one converter station. This analysis is performed by deriving the small signal model of a reference configuration consisting of a single HVDC terminal including the droop controllers. Damping ratios and achievable stability ranges of the various implementations are evaluated. More specifically, the stability limits have been analyzed and possible improvements discussed. The analysis demonstrated that the implementations coupling the ac- and dc-side dynamics are inherently ensuring a higher average damping ratio. In particular, the implementations based on the dc voltage and the ac current enable a wide stability range for a large range of droop gains while other implementations require reduced bandwidth of the converter control loops to achieve an acceptable stability range. While the analysis is presented in the context of VSC-based HVDC systems it is also valid for dc microgrids or any other dc system where droop-based voltage controllers are used.

\section{APPENDIX}

TABLE 3 BASE VALUES FOR PER UNIT SYSTEM

\begin{tabular}{|l|c|}
\hline Parameter & Value \\
\hline Rated voltage $\mathrm{V}_{\mathrm{S}, L L, R M S}$ & $220 \mathrm{~V}$ \\
\hline Rated power $\mathrm{S}_{\mathrm{b}}$ & $1200 \mathrm{MVA}$ \\
\hline Rated angular frequency $\omega_{\mathrm{b}}$ & $2 \pi 50 \mathrm{~s}^{-1}$ \\
\hline $\begin{array}{l}\text { Base value for voltage defined as } \\
\text { peak value of phase voltage, } \mathrm{V}_{\mathrm{b}}\end{array}$ & $\sqrt{2 / 3} V_{S, L L, R M S}$ \\
\hline $\begin{array}{l}\text { Base value for currents defined as } \\
\text { peak value or rated RMS, } \mathrm{I}_{\mathrm{b}}\end{array}$ & $\frac{S_{b}}{\sqrt{3} V_{S, L L, R M S}}$ \\
\hline $\begin{array}{l}\text { Base value for impedance, } \mathrm{Z}_{\mathrm{b}} \\
V_{b} / I_{b}\end{array}$ & \multicolumn{2}{|c|}{$2 \pi 50 \mathrm{~Hz}$} \\
\hline Base value for grid frequency, $\mathrm{F}_{\mathrm{b}}$ \\
\hline $\begin{array}{l}\text { Base value for angular frequency, } \\
\omega_{\mathrm{b}}\end{array}$ \\
\hline Base value for filter inductance, $\mathrm{L}_{\mathrm{b}}$ & $Z_{b} / \omega_{b}$ \\
\hline Base value for filter capacitance, $\mathrm{C}_{\mathrm{b}}$ & $\frac{1}{\omega_{b} Z_{b}}$ \\
\hline
\end{tabular}

\section{REFERENCES}

[1] European Union, Energy Roadmap 2050, Brussels, Belgium: European Union (EU), 2011

[2] A. Arapogianni, A.-B. Genachte, R. M. Ochagavia, J. P. Vergara, D. Castell, A. R. Tsouroukdissian, J. Korbijn, N. C. F. Bolleman, F. J. Huera-Huarte, F. Schuon, A. Ugarte, J. Sandberg, V. de Laleu, J. Maciel, A. Tunbjer, and R. Roth, "Deep water," The European Wind Energy Association, Jul. 2013 
TABLE 4: APPLIED PARAMETER VALUES IN PER UNIT SYSTEM

\begin{tabular}{|l|r|}
\hline \multicolumn{1}{|c|}{ Parameter } & \multicolumn{1}{c|}{ Value } \\
\hline DC source voltage, $v_{d c, b}$ & 1 p.u. \\
\hline Equivalent dc capacitor, $c_{d c}$ & 4.2 p.u. \\
\hline DC cable inductance, $l_{d c}$ & 0.5 p.u. \\
\hline DC cable resistance, $r_{d c}$ & 0.007 p.u. \\
\hline Grid voltage, $\hat{v}_{g}$ & 1.0 p.u. \\
\hline Filter inductance, $l_{f}$ & 0.08 p.u. \\
\hline Filter resistance, $r_{f}$ & 0.003 p.u. \\
\hline Filter capacitance, $c_{f}$ & 0.074 p.u. \\
\hline Grid inductance, $l_{g}$ & 0.2 p.u. \\
\hline Grid resistance, $r_{g}$ & 0.01 p.u. \\
\hline Reference dc voltage, $v^{*}{ }_{d c}$ & 0.95 p.u. \\
\hline Reference dc current, $i^{*}{ }_{d c}$ & -0.1 p.u. \\
\hline Reference ac current, $i_{l, d}^{*}$ & -0.1 p.u. \\
\hline Reference active power, $p^{*}$ & 0.4 p.u. \\
\hline Reference reactive power, $q^{*}$ & 0 p.u. \\
\hline
\end{tabular}

[3] T. Trötscher and M. Korpas, "Optimal design of a subsea power grid in the North Sea," presented at the European Offshore Wind Conference, 2009

[4] T. K. Vrana, R. E. Torres-Olguin, B. Liu, and T. M. Haileselassie, "The North Sea Super Grid - a technical perspective," presented a the 9th IET International Conference on $\mathrm{AC}$ and $\mathrm{DC}$ Power Transmission, 2010, 2010, pp. 1-5

[5] T. K. Vrana, "System Design and Balancing Control of the North Sea Super Grid," NTNU, Trondheim, 2013

[6] G. Migliavacca, Advanced Technologies for Future Transmission Grids. London: Springer Science \& Business Media, 2012

[7] T. M. Haileselassie and K. Uhlen, "Power System Security in a Meshed North Sea HVDC Grid," Proceedings of the IEEE, vol. 101, no. 4, pp. 978-990, Apr. 2013

[8] T. K. Vrana, J. Beerten, R. Belmans, and O. B. Fosso, "A classification of DC node voltage control methods for HVDC grids," Electric power systems research 2013, 2013

[9] R. T. Pinto, S. F. Rodrigues, and P. Bauer, "Comparison of direct voltage control methods of multi-terminal DC (MTDC) networks through modular dynamic models," Proceedings of the 2011-14th European Conference on Power Electronics and Applications (EPE 2011), 2011

[10] J. Liang, T. Jing, O. Gomis-Bellmunt, J. Ekanayake, and N. Jenkins, "Operation and Control of Multiterminal HVDC Transmission for Offshore Wind Farms," IEEE Trans. Power Delivery, vol. 26, no. 4, pp. 2596-2604

[11] P. Rault, F. Colas, X. Guillaud, and S. Nguefeu, "Method for small signal stability analysis of VSC-MTDC grids," 2012 IEEE Power and Energy Society General Meeting, pp. 1-7, 2012

[12] W. Wang, M. Barnes, and O. Marjanovic, "Droop control modelling and analysis of multi-terminal VSC-HVDC for offshore wind farms," presented at the 10th IET International Conference on AC and DC Power Transmission, 2012, pp. 1-6

[13] T. M. Haileselassie, T. Undeland, and K. Uhlen, "Multiterminal HVDC for Offshore Windfarms - Control Strategy," presented at the EPE Wind Energy Seminar, Stockholm, 2009

[14] O. Gomis-Bellmunt, J. Liang, J. Ekanayake, and N. Jenkins, "Voltage-current characteristics of multiterminal HVDC-VSC for offshore wind farms," Electric Power Systems Research, vol. 81, no. 2, pp. 440-450, Feb. 2011

[15] L. Xu, B. W. Williams, and L. Yao, "Multi-terminal DC transmission systems for connecting large offshore wind farms," Power and Energy Society General Meeting - Conversion and Delivery of Electrical Energy in the 21 st Century, 2008 IEEE, pp. 1-7, 2008

[16] L. Xu, L. Yao, and M. Bazargan, "DC grid management of a multiterminal HVDC transmission system for large offshore wind farms," presented at the International Conference on Sustainable Power Generation and Supply, 2009, 2009, pp. 1-7

[17] R. da Silva and R. Teodorescu, "Power delivery in multiterminal VSC-HVDC transmission system for offshore wind power applications," Innovative Smart Grid Technologies Conference Europe (ISGT Europe), 2010 IEEE PES, 2010

[18] R. da Silva, R. Teodorescu, and P. Rodriguez, "Multilink DC transmission system for supergrid future concepts and wind power integration," IET Conference on Renewable Power Generation (RPG 2011), pp. 1-6, 2011

[19] E. Prieto-Araujo, F. D. Bianchi, A. Junyent-Ferre, and O. GomisBellmunt, "Methodology for Droop Control Dynamic Analysis of Multiterminal VSC-HVDC Grids for Offshore Wind Farms," IEEE Trans. Power Delivery, vol. 26, no. 4, pp. 2476-2485

[20] F. D. Bianchi and O. Gomis-Bellmunt, "Droop control design for multi-terminal VSC-HVDC grids based on LMI optimization," presented at the 50th IEEE Conference on Decision and Control and European Control Conference, 2011, 2011, pp. 4823-4828

[21] R. T. Pinto, S. Rodrigues, P. Bauer, and J. Pierik, "Operation and control of a multi-terminal DC network," ECCE Asia, pp. 474-480, 2013

[22] B. K. Johnson, R. H. Lasseter, F. L. Alvarado, and R. Adapa, "Expandable multiterminal DC systems based on voltage droop," IEEE Trans. Power Delivery, vol. 8, no. 4, pp. 1926-1932, Oct. 1993

[23] J. Liang, O. Gomis-Bellmunt, J. Ekanayake, and N. Jenkins, "Control of multi-terminal VSC-HVDC transmission for offshore wind power," presented at the Power Electronics and Applications, 2009. EPE '09. 13th European Conference on, 2009, pp. 1-10

[24] L. Xu and L. Yao, "DC voltage control and power dispatch of a multi-terminal HVDC system for integrating large offshore wind farms," Renewable Power Generation, IET, vol. 5, no. 3, pp. 223233, 2011

[25] S. Zhou, J. Liang, J. B. Ekanayake, and N. Jenkins, "Control of multi-terminal VSC-HVDC transmission system for offshore wind power generation," presented at the Proceedings of the $44^{\text {th }}$ International Universities Power Engineering Conference , 2009, 2009, pp. 1-5

[26] T. M. Haileselassie and K. Uhlen, "Impact of DC Line Voltage Drops on Power Flow of MTDC Using Droop Control," IEEE Trans. Power Syst., vol. 27, no. 3, pp. 1441-1449

[27] T. M. Haileselassie and K. Uhlen, "Precise control of power flow in multiterminal VSC-HVDCs using DC voltage droop control," 2012 IEEE Power and Energy Society General Meeting, pp. 1-9, 2012

[28] R. L. Hendriks, G. C. Paap, and W. L. Kling, "Control of a multiterminal VSC transmission scheme for connecting offshore wind farms," European Wind Energy Conference, 2007

[29] T. M. Haileselassie and K. Uhlen, "Primary frequency control of remote grids connected by multi-terminal HVDC," Power and Energy Society General Meeting, 2010 IEEE, pp. 1-6, 2010

[30] G. Stamatiou and M. Bongiorno, "Decentralized converter controller for multiterminal HVDC grids," presented at the $15^{\text {th }}$ European Conference on Power Electronics and Applications (EPE), 2013, 2013, pp. $1-10$

[31] S. D'Arco, J. A. Suul, and M. Molinas, "Implementation and Analysis of a Control Scheme for Damping of Oscillations in VSCbased HVDC Grids," presented at the 16th International Power Electronics and Motion Control Conference and Exposition 2014, Anatalya, 2014

[32] C. Bajracharya, M. Molinas, and J. A. Suul, "Understanding of tuning techniques of converter controllers for VSC-HVDC," presented at the Proceedings of the Nordic Workshop on Power and Industrial Electronics, 2008

[33] A. B. Jusoh, "The instability effect of constant power loads," presented at the Power and Energy Conference, 2004. PECon 2004. Proceedings. National, 2004, pp. 175-179 